\title{
Attitude to and cultural determinants of exclusive breastfeeding among childbearing mothers in Nsukka urban area of Enugu State, Nigeria
}

\author{
Nkemdilim .P. Anazonwu, Chinwe .U. Nnama-Okechukwu \\ \& Inyomoma Obasi-Igwe. \\ Department of Social Work, University of Nigeria, Nsukka \\ Email: chinwe.okechukwu@unn.edu.ng
}

\begin{abstract}
Background: Exclusive breastfeeding has been found to be effective in reducing infant mortality and morbidity in the contemporary world. This study explored attitude and cultural determinants of EBF among childbearing mothers in Nsukka urban.

Data Source and Method: Data from 592 childbearing mothers were collected and analyzed using questionnaire, (SPSS), Chi-square and multiple linear regression.

Results: Attitude such as infant's inability to eat other food after EBF and that male infant should not be exclusively breastfed as well as cultural determinants such as the use of coconut water to loosen intestine and after-birth care were significant with EBF practice. The infant's inability to eat other food after EBF and after-birth care were predictors of EBF on binary logistic regression.

Conclusion: Findings suggest the need for government, healthcare and social workers to raise awareness on the risks of complementary feeding and the importance of EBF for the reduction of infant mortality and the achievement of related sustainable goals.
\end{abstract}

Keywords: Exclusive breastfeeding (EBF), Attitude, Cultural determinants, Childbearing mothers, Complementary feeding

\section{Introduction}

Globally, over two-thirds of deaths occurring during the first year of children's lives are often associated with inappropriate feeding practice, especially due to poor exclusive breastfeeding practices (EBF) during their infant stage (WHO, 20I6). Poor practices and attitudes towards EBF have been reported to be among the major reasons for poor health outcomes among children, particularly in developing countries (Vijayalakshmi, et. al., 2015). Infants, who are not exclusively breastfed, are more likely to develop gastrointestinal infections, not only in developing countries but also in industrialized countries than those that are exclusively breastfed (Niguse, Frehiwot, Dinu \& Eyerus, 2016). Studies revealed that prelacteal feeding prevalence ranges from 13 to $76 \%$ depending on the country context. This prelacteal feeding includes glucose water, infant formula, honey, cow's or buffalo's milk or water (Egata et. al., 20I3; Joshi et. al., 20I4; Onah et. al., 20I4).

According to World Breastfeeding Conference Report (2016), lack of EBF is implicated in the current high rate of child malnutrition in Nigeria, despite available initiation programs to protect, promote and support EBF. Nigeria has one of the poorest exclusive breastfeeding rates in Africa because many women give their infants water along with breast milk (Ogbebo, 20I5). Similarly, Dudu,Okoro and Otto (2016) stated that the rate of EBF has remained the lowest in Nigeria (17\%) because of certain factors such as identified traditional beliefs, practices and rites.

According to Future Assured World Breastfeeding Week Report (2017), only $37 \%$ of Nigerian women breastfeed and of these, only $25 \%$ do so exclusively. While breastfeeding initiation is on the increase at health facilities after delivery, the sustained practice of EBF once the mothers return home has remained low (Agbo, Envuladu \& Adams, 2013). For instance, among Nsukka people, a common belief around infant feeding is that exclusive breastfeeding is beneficial to both infants and mothers, but complementary feeding is essential for babies to adapt to other meals with ease. Therefore, there is need to identify the mother's attitude towards EBF and cultural determinants of EBF practice in Nsukka urban area of Enugu State.

In other words, EBF according to WHO (2014) means that the infant receives no other food or drink, 
not even water except breast milk for the first six months of life. The exceptions are oral rehydration solution (ORS), drops and syrups of vitamins, minerals or medicines. Optimal breastfeeding (early initiation of breastfeeding and exclusive breastfeeding) has the potential to prevent over 800,000 deaths ( $13 \%$ of all deaths) in children under five in the developing world (UNICEF, 20I5). Successful breastfeeding is crucial to the curbing of infant malnutrition and achieving the sustainable development goals 3 (SDG) which is geared towards good health and wellbeing. WHO (2007) opines that powdered infant formula may contain bacteria which can cause serious iillness in infant because it is not steriled. Sub-optimal EBF has been linked to an increased risk for autism spectrum disorders (ASD), attention deficit hyperactivity disorder, schizophrenia, depression, pervasive developmental disorders, and epilepsy (Al-Farsi, Al-Sharbati., Waly, Al-Farsi, Al-Shafaee, Al-Khaduri, et. al., 20I2).

Despite the acknowledged health benefits of EBF, evidence suggests that social and cultural attitudes have a strong influence on decisions around EBF practice. In other words attitude in this context refers to mother's view or behavior towards EBF practice while cultural determinants are cultural factors that affect EBF practice which include people's beliefs, practices and values. Culture and attitude of people play a role in a woman's decision to breastfeed and to continue breastfeeding. Cultural beliefs, myths and misconceptions have been highlighted as some of the challenges to optimal breastfeeding in the country and as one of the probable causes of poor breastfeeding practices in the urban slums (IFPRI, 20I4). Cultural beliefs and norms have a powerful influence on human nutrition and have been identified as among the determinants of breastfeeding practices (David, Beverley, Joseph, Angel, Helen, Francois, et. al., 20l4). Other factors of exclusive breastfeeding have been considered by different scholars, but most studies have not looked at culture beliefs and practices as an influencing factor of EBF practice. Therefore, this study is framed to (I) determine the extent mother's attitude influences the practice of EBF in Nsukka urban area; (2) examine the cultural determinants of EBF practice in Nsukka urban area.

\section{Literature review}

Understanding the importance of exclusive breastfeeding in different climes is very important in this study. This is because EBF witnesses different difficulties in many countries of the world. These include maternal health, EBF being stressful, frustrating and or painful experience due to illness or breast problems (Sohag \& Memon, 20II; Ugboaja,
Berthrand, lgwegbe et. al., 20/3). Similarly, Oluwafolahan, Olayinka and Salako (20I5) reported that there was a significant difference in the belief that breastfeeding caused nipple retraction between those who breastfed exclusively and those who did not. To buttress the point, Adugna et al. (2017) opined that the presence of breast complication was significant with the EBF practice among infants less than six months of age.

Women have reported feeling embarrassed breastfeeding in a public place, with some having been challenged by members of the public or asked to leave by business owners or staff (Bett \& Russell, 2017). Similarly, Akinremi and Folake (2015) reported that mothers believed that feeding infants with water, infant formula/cereal gruels and herbal teas within the first six months of life is a necessary stride for child survival. Also, most of the respondents agreed that breastfeeding makes mothers breast to sag while most of them felt it would be embarrassing to breastfeed in public spaces such as banks and churches but not at home. Ekanem et al. (20/2) affirmed in their study on attitude of working mothers to exclusive breastfeeding in Calabar Municipality reported that mothers have negative opinions towards breastfeeding, seeing it as embarrassing in the public while few are not willing to carry sagged breast which are likely to occur after exclusive breastfeeding and few are afraid of pains associated with breastfeeding.

Agunbiade and Ogunleye (20/2) in a study on constraints of exclusive breastfeeding practice among mothers in Southwest Nigeria reported that the perception that babies continue to be hungry after breastfeeding, maternal health problems, fear of babies becoming addicted to breast milk, pressure from mothers-in-law and grandmothers, lack of quality support from the husband, pains in the breast, and the need to return to work were the major constraints to exclusive breastfeeding. In addition, findings from their qualitative research showed that significant others played dual roles with consequences on breastfeeding practices. For instance, some felt that infants cannot feed on breast milk alone they require additional supplements such as complementary feeding that would enable a child to grow faster and herbal concoction to guard against infections. While some assist and encourage their daughters-in-law to initiate and continue breastfeeding up to one year. In affirmation, EL Kishawi, Soo, Abed and Muda (2018) reported that grandmothers and mother-in-laws encouraged the early introduction of semi-solids and water alongside breast milk to enable a child to grow faster. Mothers highlighted the role of grandmothers in providing 
breastfeeding practical support as the main influence on EBF practice.

Ugboaja et. al. (20/3) reported that women who perceived positive family attitude practiced EBF compared with those that perceived a negative family attitude towards EBF practice. They further stated that reasons for discontinuing or not practicing EBF included EBF not being culturally acceptable, husband's refusal to allow EBF or receipt of advice from elders to discontinue. In agreement, Olatubi and Olufarati (2016) reported that husbands exert influence on women's practice of exclusive breastfeeding and the duration that they practice it.

Okafor, Agwu, Okoye, Uche and Oyeoku (2017) in their study on factors associated with exclusive breastfeeding practice among nursing mothers in rural areas of Enugu State reported that nursing mothers exhibited conflict between their cultural beliefs and what they were taught by health workers. Some of the nursing mothers felt that there was no way their parents would be wrong because there were good number of healthy adults that were not exclusively breastfed. The study also added that mothers-in-law did not want EBF to be mentioned in their hearing, especially the issue of water denial when the baby was thirsty.

In spite of all these efforts as stated in the above literature to promote EBF, the practice of EBF is still low. However, most studies have been done on exclusive breastfeeding practice in different countries including Nigeria, but there is need to empirically examine mother's attitude towards EBF and cultural determinants of EBF practice in Nsukka urban area.

\section{Theoretical framework}

Theoretically, the study is hinged on the Health Belief Model (HBM). This model is based on four components: (i) Perceived susceptibility refers to a person's subjective estimation of his or her own risk of developing a particular health condition. (ii) Perceived severity is a personal judgment of the seriousness of that condition. (iii) Perceived benefits refer to a subjective estimation of the effectiveness of that recommendation in removing the threat. (iv) Perceived barriers which are also known as perceived costs refer to an individual's assessment of the obstacles to behavior change. HBM was of the view that if the anticipated benefits outweigh the anticipated costs or threat, action is likely to occur. Health Belief model will be used to interrogate the research objective to determine (I) the extent mother's attitudes influence the practice of EBF in Nsukka urban area. HBM was used to interrogate the hypothesis which states that attitude is associated with the practice of EBF. When the mother's perceived benefits of EBF outweigh the anticipated perceived barriers posed by attitudes towards EBF, mothers are likely to embrace and adopt EBF for their infants and equally change their negative attitude towards EBF practice. (2) To examine the cultural determinants of EBF practice in Nsukka urban area. HBM was used to interrogate the hypothesis which states that cultural determinants are associated with the practice of EBF. The higher the perceived threats of non-compliance to EBF by mothers due to cultural influences, the more motivated they will be in removing the threat by adopting EBF practices.

The relevance of the Health Belief Model to this study is that the higher the perceived threat on the dangers of using formula or complementary food in feeding infants by mothers, the more they will be more willing and motivated to remove the threat by adopting the practice of EBF. Also, when mother's perceived benefits outweigh their anticipated cost of formula feeding, they are likely to embrace and practice EBF for their infants. Take for instance, when infants are frequently falling sick and dying in their numbers as a result of non-adoption of EBF, mothers are more likely to embrace the practice of $E B F$ in order to reduce the death rate.

The findings will be relevant in the comprehension of the determinants of the non-practice of EBF and consequences of complementary feeding of infants in Nsukka, since EBF is the most efficient type of feeding for the first six months of life (Danso, 20I4). The result will be useful in the assessment of EBF programs in health facilities, strategic planning and evaluation of the efficacy in policy interventions aimed at improving EBF practice among mothers in Nsukka. The result will be useful for healthcare officers and social workers in sensitizing husbands, grandmothers and the entire public on the negative attitudes and cultural beliefs that influence mothers from practicing EBF, in order to ensure healthy lives and well-being which is the utmost aim of the sustainable development goals 3 .

\section{Data and methods}

Cross-sectional survey design was used in this study as it is useful to collect data from a cross-section of a population at one point in time (Babbie, 2010). The population for the study consisted of 8,458 of childbearing mothers in Nsukka urban area of Enugu State within the age range of 15 to 49 years which is in line with the World Health Organization's stipulated age for childbearing mothers (WHO, 2006). Six hundred childbearing mothers were drawn as sample size using Cochran's (1963) formula, while I8 participants (nine married men and nine grandmothers) were purposively selected for Indepth interview (IDI), giving a total of $6 / 8$ respondents. 
Mixed sampling technique was used to select respondents for the study from the three communities in Nsukka urban namely: Ihe n'Owerre, Nkpunanor and Nru. From each of these communities, one community (Owerre from lhe n'Owerre, Echara from Nkpunanor and Umuoyo from Nru) each was purposively selected in order to ensure that only the most urbanized areas in the communities were used for the study. Also, two smaller communities were purposively selected from each of the community making it six communities, that is, Amaukwaegu and Amaeze from lhe/Owerre; Amaokwe and Amaeze-Ani from Nkpunanor and Amaolu and Umugworie from Nru. In each of the two smaller communities selected, four streets were selected using SRS (balloting) that is, two streets per each community and for six communities, a total of 12 streets were selected. Ibeziako and Amobi streets from Amaukwaegu; Oloto I \& 2 and Odobido streets from Amaeze; all in Ihe/Owerre. Amaokwe Lane and Onuomozo Street from Amaokwe; Emenike Ugwuanyi Street, New Anglican and Tectonics Roads from Amaeze-Ani, all in Echara; Amalu and Umugworie from Umuoyo. Also, quota sampling was used in selecting 50 respondents from each street. Dwelling units or compounds were selected using systematic sampling with random start, and then every fifth compound was selected until the required number was obtained. In each dwelling compound, one eligible respondent was selected taking cognizance of the age from each household. When the selected street did not produce the required number, additional streets were selected using SRS from the chosen community to complete the number (600 respondents).

For the In-depth interview (IDI), nine married men and nine grandmothers that is, three married men and three grandmothers in each of the three communities were purposively selected, giving a total of six participants from each of the three communities. The three categories of men selected include opinion leaders, town union presidents and titled men because they are more knowledgeable about the community and are also decision makers in their various families. The three grandmothers were selected from the community because they influence mother's decision towards EBF.

Researcher's designed questionnaire and structured interview guide were used for data collection. This was divided into 3 sections with closed-ended questions. Section A focused on respondents' demographic data, while section B focused on information relevant to the research questions while section $C$ focused on the attitude of childbearing mothers towards EBF and cultural determinants of EBF practice, which were four points rating scale questions. Direct approach method was used by the researcher with the help of 3 research assistants to administer 600 questionnaires to the respondents. Out of 600 copies of questionnaire shared, 592 copies were correctly filled and returned.

The IDls guide served as complementary instrument for the qualitative data collection, which contained open ended with probing questions that enabled the researcher to explore the opinions on attitude and cultural determinants identified by the participants in the interview session.

\section{Variable description}

The study had two independent variables and one dependent variable. Exclusively breastfed babies find it difficult to eat other food after EBF practice; it is shameful to breastfeed in public; EBF is painful and stressful; lack of energy and strength to adopt EBF; and male infants should not be exclusively breastfed were used as indices of attitude of mothers. While, coconut water must be given to a new born baby to help loosen the intestine and reduce stomachache which EBF cannot do, after-birth care (omugwo), expressed as breast milk is harmful to the baby, baby must take cereal foods such as pap, soya beans and beverages and non-exclusive breastfed babies do not usually fall sick were used as indices of cultural determinants.

\section{Data analysis}

Data were computer processed using version 20 of Statistical Package for Social Sciences (SPSS). Percentages and frequency tables were used to present the results, while five questions each on the independent variables (attitude and cultural determinants) were tested with (practice of EBF) using Chi-square $\left(X^{2}\right)$ at $<0.05$ level of significance. The same questions were used to determine the relationship between (attitude and cultural determinants) and (practice of EBF) on four point rating scale were analyzed using multiple linear regression at $<0.05$ level of significance. Qualitative data was analyzed using verbatim quote.

\section{Results}

Socio-demographic characteristics of respondents Analysis of the socio-demographic characteristics of respondents shows that childbearing mothers (592) were used for this study, of which 30-34years were the highest in the population. For religion, majority 91.2\% of the respondents were Christians. Civil servants $(34.5 \%)$ were the majority while farmers $(0.5 \%)$ were the minority. For education, majority were secondary school certificate holders $(24.8 \%)$, while those with no formal education (I.2\%) were 
the minority. In terms of monthly income, majority of childbearing mothers (21.5\%) earned between $\mathrm{N} 26,000$ and $\mathrm{N} 50,000$. While on parity, majority had four children and above (43.5\%).

Analysis of the socio-demographic characteristics of the respondents from In-depth interviews conducted in three communities showed that (9) married men were used for this study, out of which majority $77.8 \%$ were married. For position in the community, majority $44.4 \%$ were Oziokos (titled men), while $33.3 \%$ were opinion leaders and $22.2 \%$ were town union presidents. Again, majority $55.6 \%$ were B.Sc holders. In addition, 55.6\% were Christians while II.I\% ATR. For grandmothers, majority $66.7 \%$ were married. Also, majority $44.4 \%$ were women association leaders. For education, majority $44.4 \%$ were B.Sc holders. In addition, $77.8 \%$ were Christians.

Level of EBF practice

Table 2: Level of EBF practice by mothers

\begin{tabular}{lll}
\hline Level & Frequency & Percentage (\%) \\
\hline Practiced EBF & & \\
Yes & 236 & 39.9 \\
No & 356 & 60.1 \\
Parity of exclusively breastfed children & & \\
I & 43 & 18.2 \\
2 & 76 & 32.2 \\
3 & 60 & 25.4 \\
4 and above & 57 & 24.2 \\
Duration of practiced EBF & & \\
0-2months & 6 & 2.5 \\
0-3months & 10 & 4.2 \\
0-4months & 27 & 11.4 \\
0-5months & 3 & 1.3 \\
0-6 months & 190 & 80.5 \\
\hline
\end{tabular}

Regarding EBF practice, majority (60.1\%) did not breastfeed any of their children exclusively. This finding could be as a result of certain factors such as mother's attitude and cultural practices that hinder them from adopting EBF practice for their infants. Mothers that practiced EBF adopted the practice for two children and for 6 months as recommended by
WHO. In affirmation, town union president from Nru said,

"my wife did not adopt EBF for any of our children because there is no difference between those children they breastfeed exclusively and those they did not.My children are intelligent and they do not fall sick."

Table 3: Reasons for not practicing EBF and other type of food adopted other than EBF

Reasons for not practicing EBF

I do not want my breast to fall Frequency
Percentage (\%)

17.4

Lack of family and social support

I adopted my child

Lack of proper information about EBF recommended practice and duration

Work pressure

I gave birth to twins or more

My studies do not allow me

Lack of energy and strength

It is not enough food for the baby and cannot quench thirst 
Types of food given other than EBF

\begin{tabular}{lcccccc} 
Other Types of Food Adopted & \multicolumn{2}{l}{ Responses } & \multicolumn{3}{c}{ Total (\%) } \\
& Yes & Per (\%) & No & Per (\%) \\
\hline Breast milk and artificial milk & 288 & 80.9 & 68 & 19.1 & $356(100.0)$ \\
Breast milk and water & 267 & 75.0 & 89 & 25.0 & $356(100.0)$ \\
$\begin{array}{l}\text { Breast milk, water, artificial milk, pap } \\
\text { and soya beans mixed with crayfish }\end{array}$ & 273 & 76.7 & 83 & 23.3 & $356(100.0)$ \\
$\begin{array}{l}\text { Coconut water, breast milk and herbs } \\
\text { Breast milk, water and beverages }\end{array}$ & 66 & 18.5 & 290 & 81.5 & $356(100.0)$ \\
Artificial milk, pap, water and beverages & 51 & 14.3 & 305 & 85.7 & $356(100.0)$
\end{tabular}

Data on Table 3 show that of out all the reasons mentioned by childbearing mothers in Nsukka for not practicing EBF, work pressure (19.9\%), lack of family and social support and lack of energy (I7.4\%) and sagging of breast $(14.6 \%)$ were the major reasons. This finding could be attributed to the fact that childbearing mothers in Nsukka urban are working class mothers, private firm workers, traders and artisans who are hustling to meet up with their family demand because of the economic situation of Nigeria. Or, it could be as a result of the policies in their workplaces that prevent them from taking their babies to work. As a result of this, they do not have the time to practice EBF for their infants. On the issue of the types of food given other than EBF, majority adopted mixed baby foods such as breast milk and artificial milk (80.9\%), breast milk, water, artificial milk, pap and soya beans mixed with crayfish (76.7\%) and breast milk and water (75.0\%).

A titled man from lhe n'Owerre affirmed,

"I did not allow my wife to practice EBF because my child cannot be thirsty of water for six months."

Opinion leader from Nkpunanor said,

"breast milk alone cannot sustain a new born baby. Pap, milk, soya beans, and native medicine should be given to a child for vitality and growth".

To buttress this point, another grandmother narrated,

"breastfeeding is good but the issue of not giving water for six months is not culturally acceptable. Coconut water and native herbs should be given immediately a child is born to help reduce the pain encounter when they have stomachache."
Chi-square $\left(x^{2}\right)$ result on attitude and cultural determinants of EBF

The study was designed to examine the attitude and cultural determinants of exclusive breastfeeding practice among childbearing mothers in Nsukka urban area of Enugu State, Nigeria. For this reason, ten hypotheses formulated for this study were tested in this section using chi-square $\left(x^{2}\right)$. In this section also, two independent variables were cross-tabulated with one dependent variable to test the hypotheses. The independent variables on attitude include: exclusively breastfed babies find it difficult to eat other food after EBF; it is shameful to breastfeed in public; EBF is painful and stressful; lack of energy and strength to adopt EBF and male infants should not be exclusively breastfed. Also, cultural determinants such as coconut water must be given to a new born baby to help loosen the intestine and reduce stomachache which EBF cannot do, after-birth care "omugwo", expressed breast milk is harmful to the baby, baby must take cereal foods such as pap, soya beans and beverages and non-exclusive breastfed babies do not usually fall sick.

Moreover, the variables above were re-coded as follows: under the dependent variable was "practice of EBF". To do that, respondents were asked (do you practice EBF), 'YES' were regarded as those that practiced EBF, while 'NO' were regarded as those that did not practice EBF. As a result of this, respondents that score I, practiced EBF and those that scored 2 were deemed not to practice EBF. Also, independent variables on four point rating scale were re-coded for easier understanding. Strongly agreed and agreed were re-coded as 'YES, while strongly disagreed and disagreed were recoded as "NO". 
Table 4: Result of Chi-square $\left(\mathrm{X}^{2}\right)$ analysis of attitude and cultural determinants of EBF practice. $(\mathrm{N}=592)$

\begin{tabular}{lllll}
\hline $\begin{array}{l}\text { Issues concerning mother's attitude } \\
\text { and cultural practices of EBF }\end{array}$ & Yes & No & $\chi^{2}$-cal & P-value
\end{tabular}

\section{Mother's attitude towards EBF}

Exclusively breastfed babies find it $156(26.4 \%) \quad 436(73.6 \%) \quad 70.896$

.000

difficult to eat other food after EBF

practice

It is shameful and indecent to breastfeed

$180(30.4 \%)$

$412(69.6 \%)$

14.347

.000

a baby in public

EBF is painful and stressful

$445(75.2 \%)$

$147(24.8 \%)$

.014

.494

Lack of energy and strength to adopt

$|5|(25.5 \%)$

$44 I(74.5 \%)$

.856

.203

Male infants should not be exclusively

$118(19.9 \%)$

$474(80.1 \%)$

48.199

.000

****

breastfed

\section{Cultural determinants}

Coconut water must be given to a new born baby to help loosen the intestine $\mathrm{II}(19.3 \%) \quad 478(80.7 \%) \quad 50.694 \quad .000$

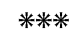
and reduce stomachache which EBF cannot do

After-birth care "omugwo"

Expressed breast milk is harmful to the baby

Baby must take cereal foods such as pap, soya bean, beverages

Non-exclusive breastfed babies do not fall sick like exclusively breastfed babies
$290(49.0 \%)$

$475(80.2 \%)$
$302(51.0 \%) \quad .161$

.375

$117(19.8 \%) \quad 1.276$
${ }^{*} p<0.05,{ }^{* *} p<0.001 ; * * * p<0.000$

Table 4 shows the calculated chi-square $\left(x^{2}\right)$ values for the following independent variables on attitude of mothers and practice of EBF; Exclusively breastfed babies find it difficult to eat other food after EBF practice $(0.000)$, it is shameful to breastfeed in public $(0.000)$ and male infants should not be exclusively breastfed $(0.000)$ were statistically significant with the practice of EBF. Since the P-values were less than .05 level of significance at I, 2 and 5 degrees of freedom respectively. This implies that lack of energy and strength to adopt EBF and male infants should not be exclusively breastfed were not statistically significant with the practice of EBF. A titled man from the n'Owerre said,

"my second child refused to eat any other food after six months of breastfeeding her exclusively. We took her to hospital and doctor said that nothing was wrong with her. My wife and I had to force her to eat any other food for the remaining six months, before she adapted to the new feeding pattern."

Another male participant from Nkpunanor lamented,

"my wife nearly died while breastfeeding our second son exclusively because of the number of times the child suck in a day and the intensity with which he sucks. 
The Table further shows the calculated Chi-square $(x 2)$ values for the following independent variables on cultural determinants and practice of EBF; coconut water must be given to a new born baby to help loosen the intestine and reduce stomachache which EBF cannot do (0.000), after-birth care "omugwo" $(0.000)$ and expressed breast milk is harmful to the baby $(0.000)$ were less than .05 level of significance at I, 2 and 3 degrees of freedom respectively. This implies that other cultural determinants such as baby must take cereal foods such as pap, soya bean, beverages and non-exclusive breastfed babies do not fall sick like exclusive breastfed babies were statistically significant with the practice of EBF. One of the grandmother from Nru said, "when I went for omugwo of my first daughter, I was told that they do not give my grandchild water because of EBF practice. I quarreled with my daughter and threatened to go back to the village if they insist on the practice. My son-in-law supported me and instructed my daughter to start giving water to the child."

To buttress this point, Town union president from Ihe n'Owerre said,

"my wife adopted EBF for our last child but when we go to work, my mother-in-law will discard the expressed breast milk kept for the baby and give water instead. Her reason was that the expressed milk is not good because the baby should suck from the mother's nipple."

Multiple linear regression result

Table 5: Regression analysis predicting the influence of attitude and cultural determinants on the practice of EBF.

\begin{tabular}{ll} 
Attitude and cultural determinants & $\begin{array}{l}\text { Standardized } \\
\text { coefficient }\end{array}$ \\
\hline
\end{tabular}

Constant Sig

.000

Coconut water must be given to a new born baby to help loosen the intestine and reduce stomachache which EBF

cannot do

After-birth care "Omugwo"

Exclusively breastfed babies find it difficult to eat other food after EBF practice

Expressed breast milk is harmful to the baby

It is shameful and indecent to breastfeed a baby in public

$E B F$ is painful and stressful

Baby must take cereal foods such as pap, soya bean and beverages

Lack of energy and strength to adopt EBF

Non-exclusive breastfed babies do not usually fall sick

Male child should not be exclusively breastfed 
Data from Table 5 show a multiple linear regression analysis on the predictors of mother's attitude and cultural determinants of EBF. Exclusively breastfed babies find it difficult to eat other food after EBF practice $(p=0.000)$ was statistically significant and strong predictor of mother's attitude towards EBF practice. While after-birth care "omugwo" $(0.01 \mathrm{I})$, expressed breast milk is harmful to the baby $(0.000)$ and baby must take cereal food such as pap, soya bean and beverages (0.023) were statistically significant and good predictors of cultural determination of EBF practice. In other words, the finding revealed that a unit change in the mother's attitude such as exclusively breastfed babies find it difficult to eat other food after EBF practice $(p=0.000)$ will result to $(-.208)$ unit changes on the practice of EBF practice. While a unit change in the cultural determination such as after-birth care "omugwo" $(0.01 \mathrm{I})$, expressed breast milk is harmful to the baby $(0.000)$ and baby must take cereal food such as pap, soya bean and beverages (0.023) will result to (-.152), (-..147) and (.089) unit changes on the practice of EBF practice. From the foregoing, it does appear that the findings in Table 5 revealed that there is likelihood in future that childbearing mothers will practice EBF as their attitude and cultural beliefs about EBF practice changed, which by implication, aids their level of EBF practice.

\section{Discussion}

According to Dudu, Okoro and Otto (2016) EBF rate in Nigeria has remained the lowest (I7\%) which was as a result of several factors and predictors such as traditional beliefs, practices, rites and early introduction of complementary feeding. Even though breastfeeding has found universal awareness and acceptability by mothers, the result of this study showed that EBF rate in Nsukka urban was found to be only (39.9\%). The EBF rate obtained in this study was, however, high compared to Nigerian rate (I7\%) as reported by Nigeria Demographic and Health Survey and other studies from Nigeria and different countries. The finding also revealed that majority of the respondents $(60.1 \%)$ affirmed that they did not practice EBF. The finding revealed a low level of EBF practice in Nsukka urban, despite the fact that EBF was the best feeding alternative for infants for the first six months, and the most effective preventive intervention to reduce early-childhood mortality and morbidity which is why government had established programs in different states to promote it (lke, 20I3; Tyndall, Kamai \& Changchangi, 2016). This finding could be a result of negative attitudes towards EBF and some cultural influences beyond the mother's control as illustrated by one of participant that denying a child water for six months is culturally unacceptable. The rate of non-practice of EBF in this study was higher compared to the findings in other studies. For instance, the findings of Ekanem et. al., (2012) in their study in Calabar municipality, Cross River State reveals that 10\% of the women never practiced EBF believing that their breast milk was insufficient for babies' need. Also, Bayissa et. al. (2015) in their study on knowledge and practice of mothers towards exclusive breastfeeding and its associated factors in Ambo Woreda West Shoa Zone Oromia Region, Ethiopia reported that 66 (I7.8\%) mothers did not practice EBF.

From the findings also, we discovered that mothers who practiced EBF were mostly those who had two children and they adopted the practice for 6 months $(32.1 \%)$ according to WHO recommended duration. The reason could be that they had seen the relevance of EBF on their first child's growth and development. The finding revealed that their reasons for not practicing EBF includes work pressure, lack of family and social support, lack of strength and energy, not enough food for the baby, fear of losing their breast shape, among others. The reasons identified in this study were in consonance with the findings of other scholars as the major reasons of not practicing EBF. For instance, Dudu et. al. (20/6) equally revealed in their study on knowledge, attitude and practice of exclusive breastfeeding by women of reproductive age in Nigeria that the rank reasons for the low EBF rate were: the breast milk was not enough food for the baby, breast pain (health issue), feeling dizzy during breastfeeding, lack of husband support and losing firmness of their breast. Ugboaja et. al. (20/3) reported that the reasons for discontinuing or not practicing EBF included husband refusal to allow EBF or advice from elders to discontinue.

From the finding, the feeding patterns that mothers mostly adopt were mixed feeding. For instance, feeding the baby with breast milk and artificial milk; breast milk, water, artificial milk, pap and soya beans mixed with crayfish; breast milk and water among others. This finding was as a result of mothers' and significant others' attitude, assumption, misconceptions and cultural belief that infants need other cereal food for growth and survival. This in line with findings of Ekanem et. al. (20I2), which revealed that $(66 \%)$ of mothers who practiced mixed feeding believed that their breast milk needs to be supplemented with artificial formulae for fast growth and health.

Studies have revealed so many attitudes exhibited by mothers towards EBF. However, this study identified new attitudes of mothers towards EBF as exclusively breastfed babies find it difficult to eat other food after EBF practice to eat other food after 
EBF practice $(p=0.000<0.05)$, and male babies should not be exclusively breastfed $(p=0.000<0.05)$. The reason for the finding could be attributed to mother's assumption that male infants suck breast a lot to the extent that mothers lose lots of energy and strength than female counterparts. As a result, mothers do not want to experience dizziness associated with the adoption of EBF for their male infants. On the other hand, mothers are of the opinion that infants that are exclusively breastfed refuse to eat other food after six months because they are addicted to the taste of breast milk alone. As a result of that, infants refuse to eat any other food given to them after six months. The significance of attitude on the practice of EBF supports the assertion that attitude of mothers towards EBF practice has greater influence on the practice of EBF. Agunbiade and Ogunleye (20I2) reported in their study that the major constraints to exclusive breastfeeding are: fear of babies becoming addicted to breast milk. Akinremi and Folake (2015) reported that most of the mothers felt that it would be embarrassing to breastfeed in public spaces, specifically banks and churches but not at home.

In the same vein, cultural determinants of EBF identified are use of coconut water to loosen babies intestine $(0.000<0.05)$ and after-birth care "omugwo" $(0.000<0.05)$ as new gap on cultural determinants of EBF practice. Culturally, people believe that coconut water should be given to an infant immediately after birth as it helps to loosen the intestine and reduce stomachache experienced by the infant as a result of colic. During this period, infants cry excessively and find it difficult to either suck breast or sleep. As such, mothers tend to avoid this discomforting stage in an infant by giving coconut water first which helps in stopping stomachache before initiating breastfeeding. Also, after-birth care "omugwo" was revealed to be significant to EBF practice because mothers-in-law (grandmothers) do not consent to denying infants water for six months when they come to take care of their daughter or daughter-in-law that put to birth. They quarrel with their daughters and daughters-in-law and even threaten to go back to the village if EBF practice would be adopted for the infant. As a result of this, mothers tend to obey their mothers and mothers-inlaw that come to take care of them and their infants after delivery to avoid leaving with annoyance. Mothers do so because those grandmothers that come for "omugwo" help in dabbing hot water on the nursing mothers and their infants, bathing the infants, baby-sitting the infants and cooking native soup that would be of help in cleansing the internal system of the nursing mothers. This finding indicates that cultural belief and practices especially grandmothers' influence and advice hinder mothers' decision on the adoption of EBF practice. Agunbiade and Ogunleye (2012) reported that pressure from mother-in-law is one of the major constraints to exclusive breastfeeding.

In the multiple linear regression analysis, attitude such as exclusively breastfed babies find it difficult to eat other food after EBF practice was significant predictors of EBF practice. From the foregoing, this finding implies that mothers who have negative or non-challant attitude that their baby would not accept to eat other food aside breast milk will not adopt EBF for their infants in order to avoid that from happening. Cultural determinants such as afterbirth care "omugwo", harmfulness of expressed breast milk to the baby and baby taking cereal foods were significantly predicted as odds for the practice of EBF. Cultural determinants do constrain mothers from adopting EBF practice for their babies because mothers tend to consent to the decision of their husbands, grandmothers and mothers-in-law on whether EBF should be adopted or not. As evidenced in this study, mothers who believe in their culture and receive advice from their grandmothers or mothers-in-law are more likely not to practice EBF. This finding is consistent with the work of Okafor et. al. (2017) in their qualitative study on nursing mothers in Enugu State, where they found that mothers-in-law do not want to hear about EBF and threaten to leave the house if EBF was adopted by their daughters-in-law because they could not ensure seeing their grandchildren being punished by their mothers because of a so-called EBF which deprived them of water and other liquids.

\section{Conclusion}

This study revealed that exclusively breastfed babies find it difficult to eat other food after EBF practice, male infants should not be exclusively breastfed, use of coconut water to help loosen the intestine and reduce stomachache which EBF cannot do and afterbirth care "omugwo" were identified gaps on attitude and cultural determinants of EBF. Also, this study has provided empirical evidence that mother's attitude and cultural beliefs and practices are associated with the practice of EBF in Nsukka urban. As such, there is urgent need for the government, non-governmental organizations, healthcare providers and social workers to rise to their responsibilities in changing people's attitude and cultural belief towards EBF especially on mothers, husbands, and grandmothers. This can be done through the introduction of effective health education through seminars, workshops and sensitization programs to eradicate the risks of complementary foods/liquids, curtail the diseases and losses of infants incurred as a result of 
not practicing EBF in order to achieve Sustainable Development Goal 3 (SDG) which is geared towards good health and wellbeing. Also, there is need for government and policy makers to make policy on the extension of maternity leave to six months in Nigeria as this would enable and encourage mothers to practice EBF as recommended by WHO. In addition, various workplaces should review their policies by providing conducive environment for nursing mothers who practice EBF either by allowing them to carry their babies to work and make provisions on where to keep the babies or giving them permission at intervals while at work to go home and breastfeed their babies if their residences are not too far away from work. Effective supervision framework should be established by government and policy makers as that will ensure that every health facility has effective and efficient EBF program viz. baby-friendly initiative program (BFHI) in order to ascertain the services they render. This is important considering the fact that some health facilities have EBF program but do not educate mothers properly on the correct duration and relevance of EBF.

\section{Reference}

Agbo, H.A., Envulade, E.A., Adams, H.S., Inalegwu, E., Okeh, E., Agbo, A. \& Zoakah, A.L. (20I3). Barriers and facilitators to the practice of exclusive breastfeeding among working class mothers: a study of female resident doctors in tertiary health institutions in Plateau State. E3 Journal of Medical Research, 2(I), I I 2-I I6.

Adugna, B., Tadele, H., Reta, F. \& Berhan, Y. (2017). Determinants of exclusive breastfeeding in infants less than six months of age in Hawassa, an urban setting, Ethiopia. International Breastfeeding Journal, I2(45), 2-8, doi:I0.II86/s|3006-017$0137-6$

Agunbiade, O.M. \& Ogunleye, O.V. (2012). Constraints of exclusive breastfeeding practice among breastfeeding mothers in Southwest Nigeria: Implication for scaling up. International Breastfeeding Journal, 7(5), 5-20, doi: I 0. I I 86/ I 746-4358-7-5

Akinremi, Z. \& Folaka, O. S. (20I5). Knowledge and attitude of exclusive breastfeeding among hair dresser apprentices in Ibadan, Nigeria. British Journal of Medicine and Medical Research, 5(3), 376-385.

Al-Farsi, Y.M., Al-Sharbati, M.M., Waly, M.L., AlFarsi, O.A, Al-Shafaee, M.A., Al-Khaduri, M.M., Trivedi, M.S. \& Deth, R.C. (20I2). Effect of suboptimal breastfeeding on occurrence of autism: a case-control study. Nutrition, 28(7), e27-e32.
Babbie, E. (20/0). Practice of social research. Belmont: Wadsworth

Bayissa, Z.B, Gelaw, B.K, Geletaw, A., Abdella, A., Chinasho, B., Alemayehu, A., Yosef, A. \& Tadele, K., (20I5). Knowledge and practice of mothers towards exclusive breastfeeding and its associated factors in Ambo Woreda West Shoa Zone Oromia Region, Ethiopia. Epidemology (Sunnyvale), 5(|82), doi: |0.4|72/2|6|-||65.1000|82

Bett, J. \& Russell, R. (2017). Breastfeeding: Attit udes and policies. Retrieved from http://www .niassembly.gov.uk/globalassets/documents/raise/p ublications/2016-2021/2017/health/0917.pdf

Cochran, W.G. (1963). Sampling techniques. (2 $2^{\text {nd }}$ ed.). New York: John Wiley and Sons Inc.

Danso, J. (20I4). Examining the practice of exclusive breastfeeding among professional working mothers in Kumasi Metropolis Ghana. International Journal of Nursing, I(I), I I-24.

David, N.C.A, Beverley, B., Joseph, C., Angel, C., Francois, G., Robert, H., Stephen, J., Sushrut, J., Alison, M., Ulrike, N., Aaron, P., Rodney, R., Graham, S., Sonu, S, Sonia, Z.S., Jakob, S.N, Linda, T., Nick, T., Anna-Maria, V., Trinley, W., James, W., Amanda C de, C.W., Chris, W., James, W. \& Katherine, W. (2014). Culture and health. Lancet, 384(9954), I607-1639, doi:10.1016/S0I406736(I4)61603-2

Dudu, J.E., Okoro, F.I. \& Otto, I. (2016). Knowledge, attitude and practice of exclusive breastfeeding by women of reproductive age in Nigeria. Imperial Journal of Interdisciplinary Research (IJIR), I(5), I67.

Egata, G., Berhane, Y. \& Worku, A. (20/3). Predictors of non-exclusive breastfeeding at 6 months among rural mothers in East Ethiopia: a community-based analytical cross-sectional study. International Breastfeeding Journal, 8(8), doi.org// 0. I I86/I 746-4358-8-8

Ekanem, I. A, Ekanem, A.P, Asuguo, A. \& Eyo, V.O. (20/2). Attitude of working mothers to exclusive breastfeeding in Calabar Municipality, Cross River, Nigeria. Journal of Food Research, I(2), 7I-75.

EL Kishawi, R.R., Soo, K.L., Abed, Y.A and Muda, W.A.M.W (2018). Assessment of exclusive breastfeeding practice among Palestinian mothers in the Gaza Strip: A mixed methods design. Asian Journal of Medicine and Health, 10(3), I-I3, doi: I0.9734/AJMAH/20I8/39292

Ike, M.N. (20I3). Utilization of exclusive breastfeeding methods among nursing mothers in Nigeria. Mediterranean Journal of Social Sciences, 4(8), 69-76 International Food Policy Research Institute (IFPRI) (20I4). Global Food Policy Report. Washington, D.C. 
Joshi, P.C., Angdembe, M.R., Das, S. K., Ahmed, S., exclusive breastfeeding and associated factors among mothers in rural Bangladesh: A cross-sectional study. International breastfeeding Journal, 9(7), doi.org// 0.1 186/1 746-4358-9-7

Niguse, T., Frehiwot, H., Dinu, A. \& Eyerus, D. (2016). Knowledge, attitude and practice towards exclusive breastfeeding among lactating mothers in Mizan Aman town, Southwestern Ethiopia: descriptive cross-sectional study. International Breastfeeding Journal, II(3), doi:I0.I|86/s|3006016-0062-0

Ogbebo, W. (2015). Nigeria has poorest exclusive breastfeeding rate in Africa. Retrieved from leadership.ng/news/45 |526/nigeria-has-poorestexclusvie-breastfeeding-rate-in-africa.

Ogbonna, C. \& Daboer, J.C. (2007). Current knowledge and practice of exclusive breastfeeding among mothers in Jos, Nigeria. Nigerian Journal of Medicine, 16 (3), 256-260.

Okafor, A.E, Agwu, P.C, Okoye, U.O., Uche, O.A, \& Oyeku, E.K. (2017). Factors associated with exclusive breastfeeding practice among nursing mothers in rural areas of Enugu State and its implication for social work practice in Nigeria. Social Work in Public Health, 33(2), |40-I48, doi.org/I0.1080/I937|918.2017.1415182.

Oluwafolahan O. S., Olayinka A. A. \& Salako, A.A. (2015). Exclusive breastfeeding and its associated factors among mothers in Sagamu, Southwest Nigeria. Journal of Health Science, 5(2): 25-3I doi:I0.5923/j.health.20I50502.0I

Olatubi, M. I. \& Olufarati, G. O. (2016). Knowledge and practice of exclusive breastfeeding among mothers attending infant welfare clinic in a tertiary health institution. Journal of Health Medicine and Nursing, 28(2016), 29-33

Onah, S., Osuorah, D.I., Ebenebe, J., Ezechukwu, C., Ekwochi, U. \& Ndukwu, I. (20/4). Infant feeding practices and maternal socio-demographic factors that influence practice of exclusive breastfeeding among mothers in Nnewi Southeast Nigeria: A cross-sectional and analytical study. International Breastfeeding Journal, 9(6), 46-69.

Sohag, A.A. \& Memon, S., (20II). Perception, practices and factors associated with exclusive
Abu, S.G.F., \& Ahmed, T. (20|4). Prevalence of breastfeeding failure. Medicial Channel, I7(4), $100-105$.

Thet, M. M., Khaing, E. E., Diamond-Smith, N., Sudhinaraset, M., Oo, S. \& Aung, T. (2016). Barriers to exclusive breastfeeding in the Ayeyarwaddy Region in Myanmar: Qualitative findings from mothers, grandmothers and husbands. Apetite, 96(2016), 62-69, doi; 10.1016/j.appet.2015.08.044

Tyndall, J.A., Kamai, R. \& Changchangi, D. (20II). Knowledge, attitude and practices of exclusive breastfeeding in Adamawa, Nigeria. American Journal of Public Health Research, 4(3), I I 2-I I 9.

Ugboaja, J.O., Nwosu, O.B., lgwegbe, A.O., ObiNwosu, A.L. (20|3). Barriers to postnatal care and exclusive breastfeeding among urban women Southeastern Nigeria. Niger Med Journal, 54(I), 45-50

UNICEF (2015). Breastfeeding. Retrieved from $h$ ttps://www.unicef.org/nutrition/index_24824.html

Vilayalakshmi, P., Susheela, T. \& Mythili, D. (2015). Knowledge, attitude and breastfeeding practices of postnatal mothers: A cross-sectional survey. International Journal of Health Science, 9(4), 364374.

WHO. (2006). Women of childbearing age who are malnourished. Retrieved from http://www.who international//malnourished women.

WHO. (2010). Early initiation of breastfeeding. WHO, Geneva.

WHO. (2007). How to prepare formula for bottlefeeding at home.

Retrieved from http://www.who.int/foodsafety/p ublications/micro/PIF_Bottle_en.pdf

WHO. (20I4). Exclusive breastfeeding. Retrievedf rom http://www.who.int/elena/titles/exclusive_br eastfeeding/en/

WHO. (2016). Exclusive breastfeeding for six months beat for the babies. Geneva

World Breastfeeding Week Report (2016). Breastfeeding: A key to sustainable development. Retrieved from worldbreastfeedingweek.org.

Future assured World Breastfeeding Week (2017). Smmary of activities conducted during 2017 wbw. Retrieved from http://futureassured.org.ng/futureassured-wbw-2017/ 